\title{
Analyzing Macroeconomic Indicators of Economic Growth using Panel Data
}

\author{
Nihat Taș ${ }^{1}$, Ali Hepșen² and Emrah Önder ${ }^{3}$
}

\begin{abstract}
During last 10 years some EU countries had economical instability. They have short and long term challenges such as unemployment, population ageing, globalization etc. In this study it is aimed to analyze macroeconomic indicators of EU countries' economic growth using panel data approach. Static linear panel data models were used for determining the effects of independent macro economic variables on gross domestic product (GDP) of EU member countries including Austria, Belgium, Bulgaria, Cyprus, Czech Republic, Denmark, Estonia, Finland, France, Germany, Greece, Hungary, Ireland, Italy, Latvia, Lithuania, Luxembourg, Malta, Netherlands, Poland, Portugal, Romania, Slovakia, Slovenia, Spain, Sweden, United Kingdom; acceding country: Croatia; and candidate countries: Iceland, Serbia and Turkey. While dependent variable of analyze is gross domestic product (volume), the independent variables are current account balance, general government gross debt, general government revenue, general government total expenditure, gross national savings, inflation (average consumer prices), population, total investment, unemployment rate, volume of exports of goods and services, volume of imports of goods and services. The analysis proposed is based on a panel data (cross sectional time series data) approach. The dataset of this research involves $31 \mathrm{EU}$ member and EU candidate countries (cross sectional units). The effects of 11 macroeconomic indicators on gross domestic product volume were examined. The findings of this research are especially useful for EU candidate countries such as Iceland, Serbia and Turkey for developing convenient economical strategies.
\end{abstract}

JEL classification numbers: C53, E00, E27, E29

Keywords: European Union and Candidate Countries, Macro Economic Parameters, Panel Data Analysis, Gross Domestic Product, Economic Growth

\footnotetext{
${ }^{1}$ Dr., Istanbul University, School of Business, Department of Quantitative Methods. Istanbul.

${ }^{2}$ Assoc.Prof.Dr., Istanbul University, School of Business, Department of Finance. Istanbul.

${ }^{3}$ Dr., Istanbul University, School of Business, Department of Quantitative Methods. Istanbul.
}

Article Info: Received : May 14, 2012. Revised: June 16, 2013.

Published online : August 15, 2013 


\section{Introduction}

The relationship between economic growth and macroeconomic indicators has long been a popular issue of debate in the literature of economic development. In this content, the primary purpose of this research is to analyze macroeconomic indicators of EU member, acceding and candidate countries' economic growth using panel data approach. Annual data are used for the period 2002 to 2012. The sample period is dependent on annual data availability. The data was gathered from the International Monetary Fund world economic outlook data base.[1] proposed new panel data approach for examined the impact of skilled emigration on human capital accumulation. The data was covering 147 countries during the period 1975-2000. Predictions were tested using dynamic regression models. They found that skilled migration prospects foster human capital accumulation in lowincome countries. [2] determined the reasons why governments privatize, and the size and extent of privatization processes around the world with using a panel of 34 countries over the 1977 - 1999 period. They identified market, budget and institutional constraints affecting privatization. [3] applied a new panel data stationary testing procedure in order to re-investigate the dynamic interactions between energy consumption per capita and real GDP per capita in 22 developed and 18 developing countries. They found that in individual countries, structural breaks occur near other variables in both developed and developing countries because of a tight relationship between energy consumption and GDP. [4] attempted to empirically evaluate that relationship with data from the transition economies of Central and Eastern Europe and the Commonwealth of Independent States. He examined various dimensions of the growth-inequality debate. His findings for transition countries indicated a strong, negative contemporaneous growth-inequality relationship. [5] applied the new heterogeneous panel co-integration technique to reinvestigate the long-run co-movements and causal relationships between tourism development and economic growth for OECD and non-OECD countries for the 19902002 period. They determined that tourism development has a greater impact on GDP in non-OECD countries than in OECD countries. [6] examined whether foreign and domestic banks in Central and Eastern Europe react differently to business cycles and banking crises. Their panel dataset comprised data of more than 250 banks for the period 1993-2000. They showed that during crisis periods domestic banks contract their credit. In contrast, Greenfield foreign banks play a stabilizing role by keeping their credit base stable. Also they found a significant and negative relationship between home country economic growth and host country credit by foreign bank subsidiaries. [7] used a panel of five Asian economies - Indonesia, Korea, Malaysia, Singapore and Thailand - over the period 1995-2007 for analyzing the links between firm survival and financial development. He found that country-level indicators of financial development have an important role to play in influencing firm survival and large firms would benefit the most from developments in the stock market, while small firms are most severely affected from high levels of financial intermediation.

\section{Macro Economic Indicators}

Our model comprises twelve variables: while dependent variable of analyze is gross domestic product (GDP); the independent variables are current account balance, general government gross debt, general government revenue, general government total 
expenditure, gross national savings, inflation (average consumer prices), population, total investment, unemployment rate, volume of exports of goods and services, volume of imports of goods and services. Gross Domestic Product represents the economic health of a country. It presents a sum of a country's production which consists of all purchases of goods and services produced by a country and services used by individuals, firms, foreigners and the governing bodies. GDP consists of consumer spending, investment expenditure, government spending and net exports hence it portrays an all inclusive picture of an economy because of which it provides an insight to investors which highlights the trend of the economy by comparing GDP levels as an index. GDP is not only used as an indicator for most governments and economic decision-makers for planning and policy formulation; but also it helps the investors to manage their portfolios by providing them with guidance about the state of the economy. On the other hand, it is good measure for an economy and with improvement in research and quality of data, statisticians and governments are trying to find out measures to strengthen GDP and make it a comprehensive indicator of national income.

International standards regarding the compilation of balance of payments statistics are described in the fifth edition of the Balance of Payments Manual prepared by the International Monetary Fund (IMF) in order to provide guidance to member countries. In a general sense, the balance of payments is a statistical statement that systematically records all the economic transactions between residents of a country (Central Government, monetary authority, banks, other sector) and nonresidents for a specific time period. The balance of payments statistics are classified under two major groups: "Current Account" and "Capital and Financial Account". In summary, the current account covers all transactions that involve real sources (including volume of exports and imports of goods and services,) and current transfers; the capital and financial accounts show how these transactions are financed (by means of capital transfer or investment in financial instruments). As mentioned in the European Economic series [8], current account deficits and surpluses are not necessarily macroeconomic imbalances in the sense of developments which are adversely affecting, or have the potential to affect the proper functioning of economies, of the monetary union, or on a wider scale. Deficits and surpluses are a natural consequence of economic interactions between countries. They show to which extent a country relies on borrowing from the rest of the world or how much of its resources it lends abroad. In this way, external borrowing and lending allows countries to trade consumption over time: a country with a current account surplus transfers consumption from today to tomorrow by investing abroad. In turn, a country with a current account deficit can increase its consumption or investment today but must transfer future income abroad to redeem its external debt. Deficits and surpluses can thus simply be the result of an appropriate allocation of savings, taking into account different investment opportunities across countries. Differences in economic prospects lead to differences in saving behavior, with brighter expectations reducing the tendency of economic agents to save and hence contributing to the accumulation of deficits. In particular, countries with a rapidly ageing population may find it opportune to save today (i.e. run surpluses) to smooth consumption over time. On the other hand, current account deficits and surpluses are part of the adjustment process in a monetary union. They absorb asymmetric shocks in the absence of independent monetary policy and nominal exchange rate adjustment.

This paper also attempts to analyze the correlation that exists between GDP and inflation. It is widely believed that there is a relationship between the two. The problem is that there 
are disagreements as to what that relationship is or how it operates. As a result, when governments make decisions based on these pieces of information, the outcome often cannot be guaranteed. Exploration of the relationship between GDP and inflation is best begun by developing an understanding of each term individually. As mentioned above, GDP is an acronym for gross domestic product, which is the value of a nation's goods and services during a specified period. This figure is generally regarded as an important indicator of an economy's health. Inflation refers the rate at which the general level of prices for goods and services is rising, and, subsequently, purchasing power is falling.

In determining the economic position of a country is through a comparison of general government gross debt, revenue, total expenditure, national savings and total investments to the gross domestic product of the country. For instance, a low government gross debt to GDP percentage is usually an indication of economic health, while a high debt to GDP percentage can indicate financial trouble for a country.

\section{Panel Data Analysis}

"Panel Data" is set of data obtained by observation of the characteristics of a variety of units (cross-sectional variables) over time [9]. Panel data set have both cross-sectional and time-series dimensions. The size of the time series is formed by monitoring the same cross-section units during a given period. When each subject (cross sectional unit) has the same number of observations, this type of panel is called a balanced panel data set. If some subjects have different number of observations, this situation is known as the unbalanced data case [10]. Panel data sets that thousands of cross sectional units observed through the time are used in many micro-economic researches [11]. Panel data provide more informative data, more variability, more degrees of freedom, less co-linearity among the variables and more efficiency [12].

Panel data analysis can be considered as a combination of regression and time series analysis [13]. This analysis is based on repetitive variance models because the observations of the units are repetitive through time dimension [14]. The main superiority of panel data due to working with the one dimensional cross-sectional series or repeated cross sectional series that same units are not observed through the time is to loosen the standard assumptions [15]. By studying the repeated cross section of observations Panel data can better detect and measure effects that cannot be observed in pure cross section or pure time series data [16]. Analyzing the observations of cross section and time series provide more flexibility compared to when used them separately by increasing the quantity and quality of data. In panel data analysis, the cross-sectional units are considered to be heterogeneous and controlled for the variation (heterogeneity). Pure time series or cross section studies which are not controlling this heterogeneity may run the risk of obtaining biased results. Panel data are able to control variables which are subject or time invariant [17]. Because panel data has time based dynamics with the observations of cross sectional data repeated through time, the effect of unmeasured variables can be controlled [18]. With the use of cross-sectional observations over time, panel data analysis provides more clarification character, less co-linearity and more degrees of freedom and efficiency than only cross sectional analysis or time series analysis [19].

In static panel data models, the covariance estimators (pooled panel data), fixed effects and random effects estimators are widely used. When the cross-sectional units are homogenous, pooled ordinary least squares panel model is used. In the presence of unit- 
specific or time-specific effects, in the case of assuming these effects to be fixed parameters to be estimated, model is called as the fixed effects. The term "fixed effects" expresses nonrandom quantities are accounted for the heterogeneity. If the subject specific effects are assumed random and not correlated with the regressors (independent variables), the model becomes random effects. These effects are included to the random effects model as a component of the error term [20]. The panel models that do not have any lagged values of the dependent or/and independent variables in the model as a regressor are called "static models".

Fixed effects model and random effects model can be shown as follow:

Fixes Effects Model:

$y_{i t}=\alpha_{i}+\sum_{k=1}^{K} \beta_{k} x_{k i t}+u_{i t}, \quad i=1, \ldots, N, \quad t=1, \ldots, T$

Random Effects Model:

$y_{i t}=\sum_{k=1}^{K} \beta_{k} x_{k i t}+\left(\alpha_{i}+u_{i t}\right), \quad i=1, \ldots, N, \quad t=1, \ldots, T$

Index $i$ differentiates the subjects and ranges from 1 to $N$. $N$ is the number of subjects. Each subject is observed $T$ times and the index $t$ differentiates the observation times through 1 to $T$. $K$ is the number of the explanatory (independent) variables.

\section{Analyzing Macro Economic Indicators Using Panel Data}

\subsection{Variables and Descriptive Statistics}

In this study, used database consists of the panel data set of 31 countries for the 20022012 periods. Dataset is a balanced panel and has $\operatorname{NxTx}(\mathrm{K}+1)=31 \times 11 \times 12=4092$ observations. Each variable has $\mathrm{NxT}=31 \times 11=341$ observations. Dependent variable is ngdp (Gross domestic product, *billion dollars) and there are 11 independent variables. Average value of ngdp for 31 countries is 504 billion dollars. Independent variables and measuring units are listed in Table 1. 
Table 1: Independent Variables and Measuring Units

\begin{tabular}{l|l|l}
\hline \multicolumn{1}{c|}{ Code } & \multicolumn{1}{c}{ Variable } & \multicolumn{1}{c}{ Units } \\
\hline bca_ngdpd & Current account balance & Percent of GDP \\
\hline lp & Population $(* 10,000,000)$ & Persons \\
\hline lur & Unemployment rate & $\begin{array}{l}\text { Percent of total labor } \\
\text { force }\end{array}$ \\
\hline pcpipch & Inflation, average consumer prices & Percent change \\
\hline tx_rpch & Volume of exports of goods and services & Percent change \\
\hline tm_rpch & Volume of imports of goods and services & Percent change \\
\hline ggxwdg_gr & Growth rate in general government gross debt & Rate \\
\hline ggr_gr & Growth rate in general government revenue & Rate \\
\hline ggx_gr & $\begin{array}{l}\text { Growth rate in general government total } \\
\text { expenditure }\end{array}$ & Rate \\
\hline ngsd_ngd & Gross national savings & Percent of GDP \\
\hline nid_ngdp & Total investment & Percent of GDP \\
\hline
\end{tabular}

Descriptive statistics for the variables used in the analysis are shown below in Table 2 . Descriptive statistics values are ordinary and there are not exceptional values in the dataset.

Table 2: Summary Statistics

\begin{tabular}{|r|rrrrr|}
\hline Variable & Obs & Mean & Std. Dev. & Min & Max \\
\hline ngdp & 341 & 503.9614 & 800.7973 & 4.303 & 3640.727 \\
bca_ngdpd & 341 & -.029675 & .067328 & -.28352 & .11852 \\
lp & 341 & 1.858403 & 2.357604 & .0288 & 8.252 \\
lur & 341 & .0883615 & .0435064 & .01014 & .25552 \\
pcpipch & 341 & .0366609 & .0385439 & -.01706 & .45134 \\
tx_rpch & 341 & .0511077 & .0796323 & -.23794 & .31648 \\
tm_rpch & 341 & .0469935 & .0990369 & -.33327 & .29259 \\
ggxwdg_gr & 341 & 1.097167 & .1719402 & .814583 & 2.736609 \\
ggr_gr & 341 & 1.063697 & .0779949 & .8267854 & 1.470259 \\
ggx_gr & 341 & 1.066551 & .0766898 & .7331372 & 1.604453 \\
ngsd_ngd & 341 & .1909255 & .058724 & -.04103 & .34076 \\
nid_ngdp & 341 & .2206239 & .0508613 & .09755 & .39959 \\
\hline
\end{tabular}

Table 3 below displays the correlation coefficients between the variables. Highest correlations among the independent variables are coefficient between tx_rpch and tm_rpch which is 0.80 ; between bca_ngdpd and ngsd_ngd which is 0.68 and between ggr_gr and ggx_gr which is 0.67 . 
Table 3: Correlation Coefficients between the Variables

\begin{tabular}{|c|c|c|c|c|c|c|c|c|c|}
\hline & ngdp & bca_ng $\sim d$ & $1 p$ & lur & pcpipch & tx_rpch & tm_rpch & ggxwdg r & $g g r$ gr \\
\hline ngdp & 1.0000 & & & & & & & & \\
\hline bca_ngdpd & 0.2523 & 1.0000 & & & & & & & \\
\hline lp & 0.8671 & 0.1296 & 1.0000 & & & & & & \\
\hline lur & -0.0561 & -0.1418 & 0.0814 & 1.0000 & & & & & \\
\hline pcpipch & -0.1781 & -0.3444 & 0.0712 & 0.0973 & 1.0000 & & & & \\
\hline tx_rpch & -0.1143 & -0.1263 & -0.0300 & 0.0952 & 0.2085 & 1.0000 & & & \\
\hline tm_rpch & -0.0812 & -0.1587 & 0.0121 & -0.0401 & 0.1792 & 0.8007 & 1.0000 & & \\
\hline ggxwdg_gr & -0.0745 & -0.1186 & -0.0601 & 0.0332 & 0.2055 & -0.1519 & -0.3249 & 1.0000 & \\
\hline$g g r$ gr & -0.2088 & -0.4142 & -0.0224 & -0.0132 & 0.5445 & 0.5022 & 0.6518 & -0.1608 & 1.0000 \\
\hline ggx_gr & -0.2049 & -0.4468 & -0.0700 & -0.0945 & 0.4881 & 0.1830 & 0.3087 & 0.1003 & 0.6678 \\
\hline ngsd_ngd & 0.0662 & 0.6783 & -0.0444 & -0.2647 & -0.2286 & 0.0428 & 0.1004 & -0.1634 & -0.1201 \\
\hline nid_ngdp & -0.2582 & -0.5400 & -0.2228 & -0.1154 & 0.1894 & 0.2140 & 0.3200 & -0.0270 & 0.4066 \\
\hline
\end{tabular}

Table 4 (continued)

\begin{tabular}{|r|rrr|}
\hline & ggx_gr & ngsd_ngd nid_ngdp \\
\hline ggx_gr & 1.0000 & & \\
ngsd_ngd & -0.1760 & 1.0000 & \\
nid_ngdp & 0.3872 & 0.2491 & 1.0000 \\
\hline
\end{tabular}

Figure 1 shows the panel line graph for the dependent variable ngdp.

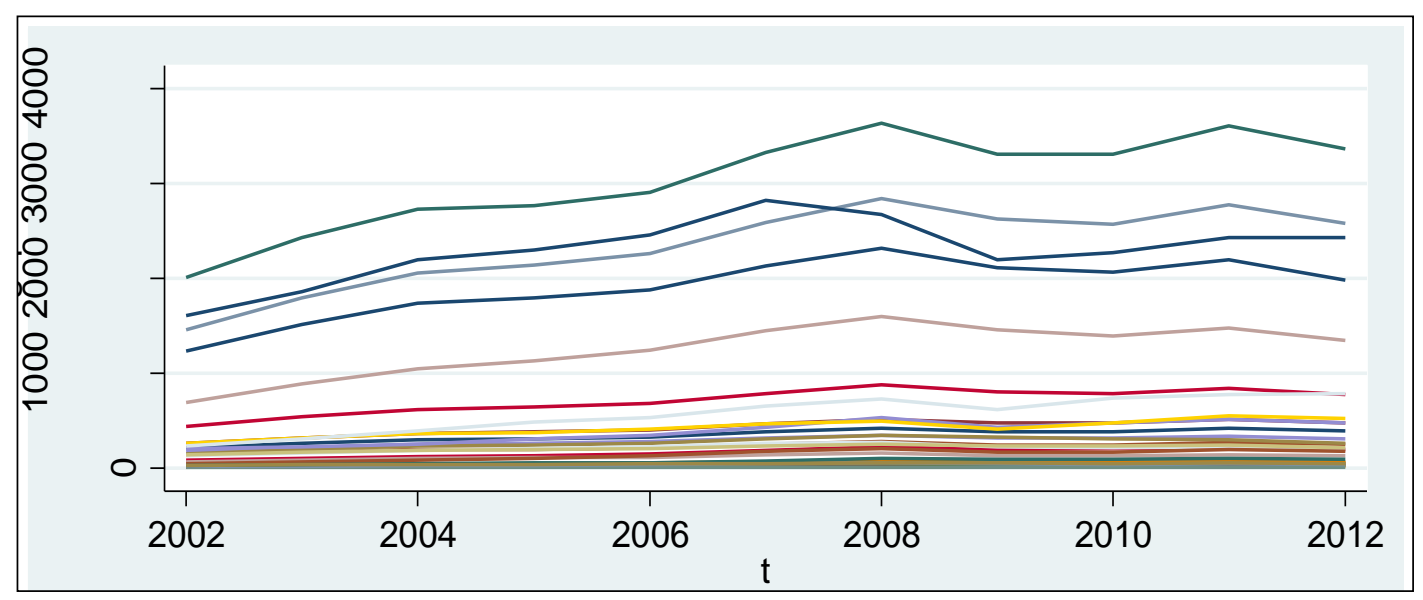

Figure 1: Panel Line Graph for the Dependent Variable ngdp

\subsection{Static Linear Panel Data Models}

To determine the relationship between the ngdp and the independent variables, the fixed effects model and the random effects model which are the most common static linear 
panel data analysis models are used. ngdp is modeled as a function of 11 factors. The fixed effects model is

$$
\begin{aligned}
& n g d p_{i t}=\alpha_{i}+\beta_{1} b c a_{-} n g d p d_{i t}+\beta_{2} l_{i t}+\beta_{3} l u r_{i t}+\beta_{4} p c p i p c h_{i t}+\beta_{5} t x_{-} r p c h_{i t}+\beta_{6} t m_{-} r p c h_{i t}+ \\
& \beta_{7} g g x w d g_{-} g r_{i t}+\beta_{8} g g r_{-} g r_{i t}+\beta_{9} g g x_{-} g r_{i t}+\beta_{10} n g s d_{-} n g d_{i t}+\beta_{11} n i d_{-} n g d p_{i t}+u_{i t}
\end{aligned}
$$

and the random effects model is

$$
\begin{aligned}
& n g d p_{i t}=\beta_{1} b c a_{-} n g d p d_{i t}+\beta_{2} l p_{i t}+\beta_{3} l u r_{i t}+\beta_{4} p c p i p c h_{i t}+\beta_{5} t x_{-} r p c h_{i t}+\beta_{6} t m_{-} r p c h_{i t}+ \\
& \beta_{7} g g x w d g_{-} g r_{i t}+\beta_{8} g g r_{-} g r_{i t}+\beta_{9} g g x_{-} g r_{i t}+\beta_{10} n g s d_{-} n g d_{i t}+\beta_{11} n i d_{-} n g d p_{i t}+\left(\alpha_{i}+u_{i t}\right)
\end{aligned}
$$

$i$ stands for the country number, $t$ stands for the year, $u_{i t}$ is the error term for the fixed effects model and $\left(\alpha_{i}+u_{i t}\right)$ is the composite error term for the random effects model. If the country effects are uncorrelated with the regressors, they are known as random effects. In the random effects model, because there is no correlation between the country specific effects and the regressors, country specific effects are parameterized as additional random disturbances. If the country effects are correlated with the regressors, then they are known as fixed effects. If there is no country specific effect in the model, then the model becomes as the pooled ordinary least squares regression which is

$$
\begin{aligned}
& n g d p_{i t}=\mu+\beta_{1} b c a_{-} n g d p d_{i t}+\beta_{2} l p_{i t}+\beta_{3} l u r_{i t}+\beta_{4} \text { pcpipch }_{i t}+\beta_{5} t x_{-} r p c h_{i t}+\beta_{6} t m_{-} r p c h_{i t}+ \\
& \beta_{7} g g x w d g_{-} g r_{i t}+\beta_{8} g g r_{-} g r_{i t}+\beta_{9} g g x_{-} g r_{i t}+\beta_{10} n g s d_{-} n g d_{i t}+\beta_{11} n i d_{-} n g d p_{i t}+u_{i t}
\end{aligned}
$$

Firstly, the null hypothesis that constant terms are equal across countries is tested to determine if the pooled ols regression will produce inconsistent estimates. Pooling test examines whether the intercepts take on a common value $\alpha$ and also known as the test for heterogeneity. Hypothesis is tested with $F$ test

Table 5: Testing for the Country Specific Effects

$$
\begin{aligned}
& H_{0}: \alpha_{1}=\alpha_{2}=\ldots=\alpha_{N} \\
& F(30 ; 299)=53.51 \text { prob }>F=0.0000 \\
& \hline
\end{aligned}
$$

and the $p$ value is 0.0000 . Null hypothesis is rejected. This provides strong evidence for the case for retaining country specific effects in the model specification. So, the pooled ordinary least squares model is inconsistent. The Pooled ols model (OLS_ALL), the fixed effects model (FE_ALL) and the random effects model (RE_ALL) results are shown respectively in the Table 6 . 
Table 6: Pooled OLS, Fixed Effects and Random Effects Models

\begin{tabular}{|c|c|c|c|}
\hline Variable & OLS_ALI & FE_ALI & RE_ALI \\
\hline \multirow[t]{3}{*}{ bca_ngdpd } & -2262.4661 & -226.33522 & -1109.0438 \\
\hline & 4370.5294 & 1857.8225 & 2124.4992 \\
\hline & 0.6050 & 0.9031 & 0.6017 \\
\hline \multirow[t]{3}{*}{$1 p$} & 301.64765 & 1307.4635 & 321.11738 \\
\hline & 8.1437477 & 117.2346 & 21.354954 \\
\hline & 0.0000 & 0.0000 & 0.0000 \\
\hline \multirow[t]{3}{*}{ lur } & -1999.2071 & -1265.4896 & -1035.926 \\
\hline & 453.07528 & 423.61627 & 445.29327 \\
\hline & 0.0000 & 0.0030 & 0.0200 \\
\hline \multirow[t]{3}{*}{ pcpipch } & -3815.9149 & 433.10129 & -511.81024 \\
\hline & 637.28187 & 315.38152 & 345.09672 \\
\hline & 0.0000 & 0.1707 & 0.1380 \\
\hline \multirow[t]{3}{*}{$t x \_r p c h$} & 300.14161 & -96.767791 & 7.3488318 \\
\hline & 410.33191 & 178.34864 & 203.62366 \\
\hline & 0.4650 & 0.5878 & 0.9712 \\
\hline \multirow[t]{3}{*}{ tm_rpch } & -322.03228 & 53.95787 & -49.725872 \\
\hline & 394.86506 & 170.45905 & 194.31987 \\
\hline & 0.4153 & 0.7518 & 0.7980 \\
\hline \multirow[t]{3}{*}{ ggxwdg_gr } & 28.853357 & 64.067478 & 50.45071 \\
\hline & 123.78207 & 58.362333 & 66.448925 \\
\hline & 0.8158 & 0.2732 & 0.4477 \\
\hline \multirow[t]{3}{*}{$g g r$ gr } & -719.79669 & 80.987428 & -85.169113 \\
\hline & 461.1889 & 201.15488 & 229.66851 \\
\hline & 0.1195 & 0.6875 & 0.7108 \\
\hline \multirow[t]{3}{*}{$g g x_{\text {I }} g r$} & -5.9833848 & -297.12541 & -270.85056 \\
\hline & 356.36172 & 160.88146 & 183.05769 \\
\hline & 0.9866 & 0.0658 & 0.1390 \\
\hline \multirow[t]{3}{*}{ ngsd_ngd } & 2695.1518 & 799.33888 & 1138.2268 \\
\hline & 4356.2346 & 1837.575 & 2106.3063 \\
\hline & 0.5365 & 0.6639 & 0.5889 \\
\hline \multirow[t]{3}{*}{ nid_ngdp } & -2437.9341 & -535.27354 & -1057.3717 \\
\hline & 4385.0456 & 1876.4762 & 2146.4956 \\
\hline & 0.5786 & 0.7756 & 0.6223 \\
\hline \multirow[t]{3}{*}{ _cons } & 956.24528 & -1708.2562 & 326.62786 \\
\hline & 473.76334 & 350.40975 & 303.98464 \\
\hline & 0.0444 & 0.0000 & 0.2826 \\
\hline
\end{tabular}

Also, the null hypothesis that the variances of the country specific effects are equal to zero is tested by the Lagrange Multiplier test and the null hypothesis that the standard deviations of the country specific effects are equal to zero is tested by the Likelihood Ratio test. Results are given in the Table 7.

Table 7: The Lagrange Multiplier and the Likelihood Ratio Test Results

\begin{tabular}{ll}
\hline Lagrange Multiplier Test & Likelihood Ratio Test \\
\hline$H_{0}: \sigma_{\alpha_{i}}^{2}=0$ (Pooled ols regression is & $H_{0}: \sigma_{\alpha_{i}}=0$ (Pooled ols regression is \\
appropriate.) & appropriate.) \\
$L M \quad \chi_{1}^{2}=1014.36 \quad$ prob $>\chi^{2}=0.0000$ & $\chi_{1}^{2}=460.78 \quad$ prob $>\chi^{2}=0.0000$ \\
\hline
\end{tabular}

Because there is country specific effects, pooled ols model shown in the first column is inappropriate. Most of the regressors are not significant. Finally 3 of all independent variables are significant and by using these regressors which are lp, lur and ggx_gr, the 
fixed and the random effects models are estimated and the results are shown in the first two coloumns of the Table 8 below.

Table 8: Static Linear Panel Data Models

\begin{tabular}{|r|rrrrr|}
\hline Variable & \multicolumn{1}{|c}{ FE } & \multicolumn{1}{c}{ RE } & FE_RB & FE_PCSE & FE_DK \\
\hline lp & 1197.3581 & 341.39549 & 1197.3581 & 285.99362 & 1197.3581 \\
& 106.32105 & 26.803482 & 403.34191 & 23.468885 & 248.13309 \\
& 0.0000 & 0.0000 & 0.0058 & 0.0000 & 0.0000 \\
Iur & -1184.4394 & -929.58167 & -1184.4394 & -1825.0088 & -1184.4394 \\
& 33.84411 & 357.12541 & 494.79103 & 353.80452 & 230.59185 \\
ggx_gr & 0.0004 & 0.0092 & 0.0231 & 0.0000 & 0.0000 \\
& -280.13589 & -349.138 & -280.13589 & -396.77413 & -280.13589 \\
& 135.07513 & 147.50442 & 108.78589 & 124.34375 & 71.993731 \\
_cons & 0.0389 & 0.0179 & 0.0152 & 0.0014 & 0.0005 \\
& -1317.7746 & 324.02372 & -1317.7746 & 542.47688 & -1317.7746 \\
& 252.77713 & 192.98142 & 721.32216 & 150.79341 & 474.06457 \\
& 0.0000 & 0.0931 & 0.0777 & 0.0003 & 0.0093 \\
\hline
\end{tabular}

The random effects model specifies the country specific effects as a random draw that is uncorrelated with the regressors and the overall error term. The random effects estimator uses the assumption that the country specific effects are uncorrelated with the regressors and the extra orthogonality conditions are valid. This assumption is tested by using Hausman test and the results are given in Table 9.

Table 9: Hausman Specification Test Results

\begin{tabular}{cccc}
\hline Variable & $\begin{array}{c}\text { Fixed Effects } \\
(\mathrm{b})\end{array}$ & $\begin{array}{c}\text { Random Effects } \\
(\mathrm{B})\end{array}$ & $\begin{array}{c}\text { Difference } \\
(\mathrm{b}-\mathrm{B})\end{array}$ \\
\hline $\mathrm{lp}$ & 1197.36 & .341 .40 & 855.96 \\
lur & -1184.44 & -929.58 & -254.86 \\
ggx_gr & -280.14 & -349.14 & 69.00 \\
\hline$H_{0}$ : Differences in coefficients are not systematic. (the RE estimator is consistent) \\
$\chi_{3}^{2}=(b-B)^{\prime}\left[\left(V_{b}-V_{B}\right)^{-1}\right](b-B)=67.83$ \\
\\
\multicolumn{4}{c}{ prob $>\chi^{2}=0.0000$} \\
\hline
\end{tabular}

The Hausman test's null hypothesis is rejected. Country specific effects are correlated with the regressors. Because the random effects estimator is inconsistent, the fixed effects model is the appropriate one.

Before using the the fixed effects model, diagnostic tests for the model assumption must be performed. The most important assumptions of the fixed effects estimator are homoscedasticity, no serial correlation and no contemporaneous correlation. Testing for homoscedasticity is performed by using modified Wald test for the null hypothesis of homoscedasticity against the heteroscedastic alternative. Testing for serial correlation is performed by using Baltagi-Wu locally best invariant test, modified Bhargava et.al. Durbin Watson test and Wooldridge's serial correlation test respectively. For testing the absence of the contemporenaous correlation assumption, Breusch-Pagan Lagrange 
Multiplier test, Pesaran CD test, Friedman's R test and Frees' Q test are performed. Test results are given below in Table 10 .

Table 10: Results of the Diagnostic Tests

\begin{tabular}{llll}
\hline Test & Hypothesis & Test Statistic & Probability \\
\hline Homoscedasticity & & & \\
Modified Wald & $H_{0}: \sigma_{i}^{2}=\sigma^{2}$ & $\chi_{31}^{2}=5.8 * 10^{5}$ & $p>\chi_{31}^{2}=0.0000$
\end{tabular}

\section{Serial Correlation}

Baltagi-Wu LBI.

$$
H_{0}: \rho=0
$$$$
L B I=0.8299
$$

Modif.

Bhargavaet.al. DW

$H_{0}: \rho=0$

$D W=0.4144$

Wooldridge's

Serial Correlation

$H_{0}:$ No first order serial

$F_{1: 30}=909.67$

$p>F_{1,30}=0.0000$ correlation

\section{Contemporaneous \\ Correlation}

Breusch-Pagan LM

$H_{0}$ :No contemporaneous

$\chi_{465}^{2}=1838.14 \quad p>\chi_{465}^{2}=0.0000$ correlation

Pesaran CD

$H_{0}$ : No contemporaneous

$C D=22.53$

$p>C D=0.0000$

correlation

Friedman's R

$H_{0}$ : No contemporaneous

$R=106.31$

$p>R=0.0000$ correlation

Frees' Q

$$
H_{0} \text { : No contemporaneous } \quad Q_{\text {test }}=7.89
$$

correlation

Critical Values from Frees' Q distribution:

$$
\begin{array}{ll}
\alpha=0.10 & : 0.2333 \\
\alpha=0.05 & : 0.3103 \\
\alpha=0.01 & : 0.4649
\end{array}
$$

Because the Modified Wald test $p$ value is 0.0000 , the null hypothesis is rejected and the model has heteroscedasticity. For serial correlation, Wooldridge' serial correlation $F$ test statistic is 909.67 and the $p$ value is 0.0000 . Model has serial correlation problem. Additionally both Baltagi-Wu LBI and modified Bhargava et. al. DW serial correlation test statistics which are 0.8299 and 0.4144 respectively indicate that the model has serial correlation problem. All tests performed for the contemporenaous correlation point that there is cross sectional correlation in the model.

The last three columns of the Table 8 shows the fixed effects model with the Huber-White standard errors that is robust to heteroscedasticity and serial correlation (FE_RB); the fixed effects model with panel corrected standard errors that is robust to heteroscedasticity and the cross sectional (contemporaneous) correlation (FE_PCSE); the 
fixed effects model with the Driskoll-Kraay standard errors that is robust to the heteroscedasticity, serial correlation and to the cross sectional correlation (FE_DK).

FE, FE_RB and the FE_DK models have the same coefficient estimates with the different standard errors. The FE_PCSE model has different coefficient estimates from the other three models. Finally, because of the violations of the assumptions and the nature of the model estimators, the last model can be used to interpret the relationship between the dependent variable and the regressors (independent variables).

The coefficient of $\mathrm{lp}$ (1197.36) indicates that if the population increases 10 million, the dependent variable gross domestic product (ngdp) increases about 1.2 billion dollars. Because the coefficient of lur is -1184.44 , if the unemployment rate increases $1 \%$, the gross domestic product decreases about -11.84 billion dollars. The estimated coefficient of the ggx_gr is -280.14 and it can be interpreted as if the growth rate in general government total expenditures increases $1 \%$, the gross domestic product decreases about 2.80 billion dollars.

\section{Conclusion and Suggestions}

In this paper the authors used panel data approach to analyze the individual effect of some of the key macroeconomic indicators (current account balance, general government gross debt, general government revenue, general government total expenditure, gross national savings, inflation (average consumer prices), population, total investment, unemployment rate, volume of exports of goods and services, volume of imports of goods and services) on economic growth (GDP) of EU, acceding and candidate countries over during the 2002-2012 period. The main findings of static model indicate that level of population positively affects economic growth. That is, 10 million increase in population leads to rise in GDP over 1.2 trillion dollars. Whereas the level of unemployment rate and total expenditure negatively affect economic growth. One percent increase in the unemployment rate decreases GDP by 11.8 billion dollars and one percent increase in the total expenditure decreases GDP by 2.80 billion dollars.

\section{References}

[1] M. Beine, F. Docquier and C. Oden-Defoort, A panel data analysis of the brain gain, World Development, 39(4), (2011), 523-532.

[2] B. Bortolotti, M. Fantini and D. Siniscalco, Privatisation around the world: Evidence from panel data, Journal of Public Economics, 88, (2003), 305-332.

[3] C.C. Lee and C.P. Chang, Energy consumption and GDP revisited: A panel analysis of developed and developing countries, Energy Economics, 29, (2007), 1206-1223.

[4] G. Sukiassyan, Inequality and growth: What does the transition economy data say?, Journal of Comparative Economics, 35, (2007), 35-56.

[5] C.C. Lee and C.P. Chang, Tourism development and economic growth: A closer look at panels, Tourism Management, 29, (2008), 180-192.

[6] R. de Haas and I. van Lelyveld, Foreign banks and credit stability in Central and Eastern Europe: A panel data analysis, Journal of Banking and Finance, 30, (2006), 1927-1952. 
[7] S. Tsoukas, Firm survival and financial development: Evidence from a panel of emerging Asian economies, Journal of Banking and Finance, 35, (2011), 17361752.

[8] European Union, Current Account Surpluses in the EU, European Economic Series, September 2012.

[9] S.C. Ahn and H.R. Moon, Large-N and Large-T properties of panel data estimators and the Hausman test, USC-CLEO Research Paper, No C01-20, 2001.

[10] J.M. Wooldridge, Introductory Econometrics, 4th press, South Western Cengage Learning, Canada, 2009.

[11] R.C. Hill, W.E. Griffiths and G.C. Lim, Principles of Econometrics, 3rd press, John Wiley \& Sons, 2008.

[12] B.H. Baltagi, Econometric Analysis of Panel Data, 4th Edition, John Wiley\&Sons Ltd, 2010.

[13] E.W. Frees, Longitudinal and Panel Data, Analysis and Applications in the Social Sciences, Cambridge University Press, New York, 2004.

[14] M.V. Pazarlığlu, 1980-1990 Döneminde Türkiye'de İç Göç Üzerine Ekonometrik Model Çalışması, V. Ulusal Ekonometri ve İstatistik Sempozyumu, Çukurova Üniversitesi, Adana (In Turkish), 2001.

[15] G.S. Maddala and K. Lahiri, Introduction to Econometrics, 4th press, John Wiley \& Sons, West Sussex, 2009.

[16] D.N. Gujarati and D.C. Porter, Basic Econometrics, 5th Edition, McGraw Hill, New York, 2009.

[17] B.H. Baltagi, Econometric Analysis of Panel Data, 4th Edition, John Wiley\&Sons Ltd, 2010.

[18] C. Hsiao, Analysis of Panel Data, 2nd press, Cambridge University Press, New York, 2003.

[19] R. Tari, Ekonometri, Umuttepe Kitabevi, 6th Edition, Kocaeli (In Turkish), 2010.

[20] B.H. Baltagi, Econometric Analysis of Panel Data, 4th Edition, John Wiley\&Sons Ltd, 2010. 